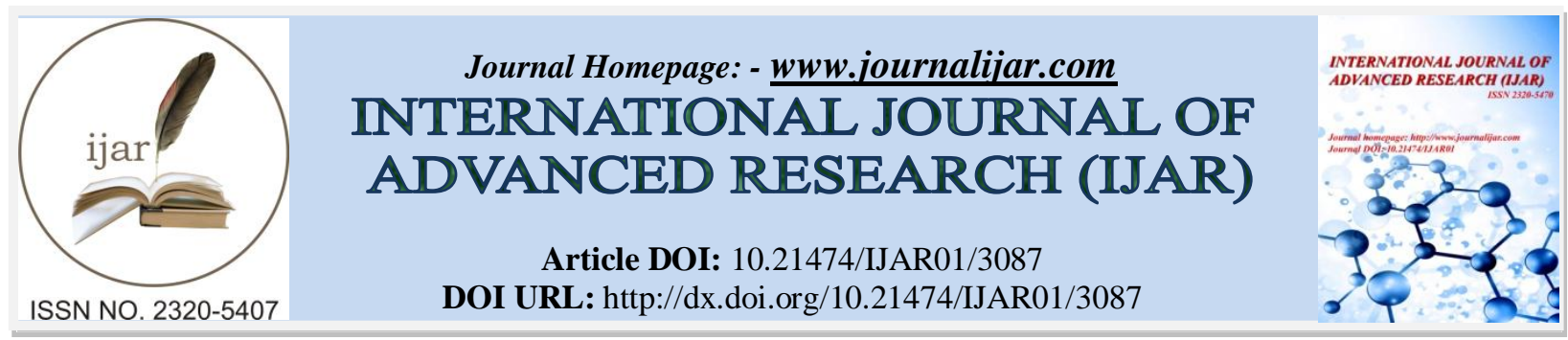

RESEARCH ARTICLE

\title{
EFFECT OF INDEPENDENCE VARIABLES ON EMPOWERMENT OF SHG MEMBERS THROUGH ENTREPRENEURIAL ACTIVITIES AND LOAN PRACTICES ADOPTED
}

Anchal Sharma and Smita Tripathi

College of Home Science Chandra Shekhar Azad University of Agriculture \& Technology Kanpur (U.P.)

\section{Manuscript Info}

Manuscript History

Received: 03 November 2016

Final Accepted: 28 December 2016

Published: January 2017

Key words:-

Independent variables, empowerment, entrepreneurial activities.

\section{Abstract}

Empowerment is a process, which generates changes in ideas and perceptions and creates awareness about one's rights and opportunities for self-development in all important spheres of life. It enables individuals and groups to change the balance of power by way of knowledge, know-how and experience to strengthen one's capacity and self-reliance. Many factors affect empowerment level of women such as caste, family's socio-economic status, custom, culture, age and education of family members as well as women's herself etc. Thus the study was conducted to know the role of SHGs participation in women empowerment. Random Sampling techniques were used and total 240 women respondents were selected to three blocks of Kanpur District. The study revealed that as age increases with co relation coefficient of $0.2436,0.2447,0.2478$ and 0.3280 . Occupation was observed significantly positively correlated with economic, sociocultural and politico-legal empowerment. Sharma and Sharma (2010) stated that for Indian rural womenfolk, micro-finance is all about self-sufficiency, employment creation, income generation, social safety as well as sustainable livelihood of the of the poor women's group. Micro-finance intertwines two major pillars of India viz., democracy and micro-entrepreneurship at the grass root level.

Copy Right, IJAR, 2016,. All rights reserved.

\section{Introduction:-}

Now-a-days economic development is one of the factors that have changed the entire scenario of social and cultural environment within the country especially for the women. Women empowerment has been recognized as the central issue in determining the status of women and it has been considered as one of the strategies to tackle the socioeconomic poverty. Women have taken up self-help movement through savings as a mass movement. Development agenda of the country in the last few years placing the people, especially women, in the forefront has enabled formation of a large number of SHGs throughout the country. The ultimate objective of all these efforts is to make women economically independent and self-reliant- Many factors affect empowerment level of women such as caste, family's socio-economic status, custom, culture, age and education of family members as well as women's herself etc. Economic empowerment is one of the approaches which have been widely used with women empowerment. One can be empowered either externally by capacity building or internally by developing selfexpression, both are interdependent/ Control and management of resources develops the ability for self-expression in various ways as self- confidence, ability of decision making, skill overcome external barriers for accessing resources 
etc. women must go through intrinsic transformations regarding knowledge, skill and understanding which can be enhanced by group method which also involves empowerment of an individual. Many factors affected their choice of work as interest and educational background, family, social status, income level, technical knowledge, entrepreneurial background etc. Some activities like hand-made papers, bee-keeping, making of soap, jiggery, pulse processing, fruit processing and preservation, bamboo and cane work, weaving of doormats, manufacturing of candles etc. considered and identified as the convenient entrepreneurial activities for housewives. The SHG bank linkage programme is unique but faces several challenges regarding sustainability of the programme. The first and foremost challenge is how to maintain the quality of SHGs when there is mushroom increase in their number. The poor quality is seen in the book keeping, audit of groups in the country, which are accumulating regular savings, undertakes credit functions by means of intrinsic resources and credit from banks successfully. Nagayya and Rao (2009) reviewed the SHGs-Bank linage programme at national and state level with special reference to Andhra Pradesh in detail and certain aspects of other three southern states-Tamil Nadu, Karnataka and Kerala. Banks have an important role to play and stake in inclusive banking in stepping up the success rate in the functioning of SHGs and support organizations of various categories. Self-help promotional Institutions and banks should pursue the task of spreading healthy management practices among SHGs, uniformly in developed and less developed regions. Dutta and Panda (2009), indicated that Impact Assessment is the structured study, which measures the impact on employment, income generation, nutrition, education, health, consumption, business development (micro entrepreneurship) and gender equity on MFI's clients. Impact assessment refers to the assessment of how financial products and services affected the lives of the poor. Impact assessment is the measurement of the income growth, assets growth and vulnerability reduction of the poor by the microfinance programme. The indicators for impact assessment are not limited to economic development but extended to developmental growth like health, education, empowerment, gender, etc. Estaple and Torreguitart (2010) studied about the effects of micro-finance in developed countries, and specifically the start-up of micro-business by women entrepreneurs with limited access to credit, having benefit from a micro-credit programme to developed their self-employment projects. as a part of general project to try to understand the impact of the existing micro-finance institutions (MFIs).The present research aims to study the social impact of the micro-business started up by women entrepreneurs granted with micro-loans, by means of a qualitative approach, the study proposed involves a total of ten women, clients of three different MFIs based in catatonia. Semi-structured interviews have been used to conduct the research. The results have been analysed with the help of a frame. Work in which parameters related to the women micro-entrepreneurs, to their entrepreneurship experiences, and to the MFIs granting their loans are regarded as indicators of the personal and family impacts, of their professional lives and of the social impacts of micro-finance. The observed impacts are mostly related to personal and family issues, on account of the limited capacity of the micro-credit instrument to better the women's standard of living. Social impacts, although expected to be marginal, are also revealed by the study.

\section{Research Methodology:-}

Present study on "Effect of independence variables on empowerment of SHG members through entrepreneurial activities and loan Practices adopted" was conducted in rural areas of Kanpur District. Three blocks namely Chaubepur, Shivrajpur and Kalyanpur were purposively selected from the study areas. 8 villages were than purposively selected from each blocks to get a total of 24 villages. One SHG from each village and 10 respondents from each SHG was randomly selected to get a total of 240 respondents.

\section{Results \& Discussion:-}

The present study were based on two main objectives such as Socio-Personal the respondents and empowerment of rural women through Self Help Group. Majority, about forty- three per cent respondents were belonging to 35 to 45 years of age followed by 28.75 per cent were of 25 to 35 years. About twenty- five per cent respondents were educated up to high school whereas, 16.66 per cent respondents were educated up to middle school. Majority, (47.08\%) respondents were belonging to OBC caste followed by 31.66 per cent respondents were of SC/ST category. Majority $(63.75 \%)$ respondents were belonging to joint family and about forty-nine per cent respondents were having 5 to 8 members in their family. More than forty per cent respondents were having thepucca house and 34.16 percent heads of family were labour. 
Part I:- Personal and socio-economic characteristics N $=240$

\begin{tabular}{|c|c|c|c|}
\hline S.No & Personal Profile & Frequency & Percent \\
\hline & \multicolumn{3}{|c|}{ Age } \\
\hline 1 & $<25$ & 37 & 15.41 \\
\hline 2 & $25-35$ & 69 & 28.75 \\
\hline 3 & $35-45$ & 103 & 42.91 \\
\hline \multirow[t]{3}{*}{4} & $>45$ & 31 & 12.91 \\
\hline & Total & 240 & 100.0 \\
\hline & \multicolumn{3}{|c|}{ Educational Level } \\
\hline 1 & Illiterate & 29 & 12.08 \\
\hline 2 & Read and write only & 36 & 15.00 \\
\hline 3 & Primary & 36 & 15.00 \\
\hline 4 & Middle school & 40 & 16.66 \\
\hline 5 & High school & 67 & 27.91 \\
\hline \multirow[t]{3}{*}{6} & Intermediate and above & 32 & 13.33 \\
\hline & Total & 240 & 100.0 \\
\hline & Caste & & \\
\hline 1 & General & 51 & 21.25 \\
\hline 2 & $\mathrm{OBC}$ & 113 & 47.08 \\
\hline \multirow[t]{3}{*}{3} & $\mathrm{SC} / \mathrm{ST}$ & 76 & 31.66 \\
\hline & Total & 240 & 100.0 \\
\hline & \multicolumn{3}{|c|}{ Type of Family } \\
\hline 1 & Joint & 153 & 63.75 \\
\hline \multirow[t]{3}{*}{2} & Nuclear & 87 & 36.25 \\
\hline & Total & 240 & 100.0 \\
\hline & Size of Family & & \\
\hline 1 & Up to 4 members & 69 & 28.75 \\
\hline 2 & 5 to 8 members & 117 & 48.75 \\
\hline \multirow[t]{3}{*}{3} & Above 8 members & 54 & 22.50 \\
\hline & Total & 240 & 100.0 \\
\hline & Type of House & & \\
\hline 1 & Kaccha & 49 & 20.41 \\
\hline 2 & Pucca & 102 & 42.50 \\
\hline \multirow[t]{3}{*}{3} & Mixed & 89 & 37.08 \\
\hline & Total & 240 & 100.0 \\
\hline & \multicolumn{3}{|c|}{ Occupation of head of family } \\
\hline 1 & Labour & 82 & 34.16 \\
\hline 2 & Caste occupation & 39 & 16.25 \\
\hline 3 & Farmers & 24 & 10.00 \\
\hline 4 & Business & 51 & 21.25 \\
\hline 5 & Service & 44 & 18.33 \\
\hline & Total & 240 & 100.0 \\
\hline
\end{tabular}


Table 2:- Distribution of Respondent on the Basis of Loan Practices Adopted N = 240

\begin{tabular}{|c|c|c|c|}
\hline S.No. & Loan Practices & Frequency & Per cent \\
\hline & \multicolumn{3}{|c|}{ Number of loan taken by SHGs members } \\
\hline 1 & One & 101 & 42.08 \\
\hline 2 & $2-4$ & 55 & 22.91 \\
\hline 3 & $4-6$ & 56 & 23.33 \\
\hline \multirow[t]{3}{*}{4} & More than 6 & 28 & 11.66 \\
\hline & Total & 240 & 100.00 \\
\hline & Size of the latest loan & & \\
\hline 1 & Less than 5000 & 136 & 56.66 \\
\hline 2 & 5000 to 10000 & 68 & 28.33 \\
\hline 3 & 10000 to 15000 & 30 & 12.50 \\
\hline \multirow{3}{*}{4} & 15000 and more & 6 & 2.50 \\
\hline & Total & 240 & 100.00 \\
\hline & Amount of loan borrowed from banks & & \\
\hline 1 & Up to 5000 & 74 & 30.83 \\
\hline 2 & 5000 to 10,000 & 55 & 22.91 \\
\hline 3 & 15,000 to 25,000 & 52 & 21.66 \\
\hline 4 & 25,000 to 40,000 & 38 & 15.83 \\
\hline \multirow[t]{3}{*}{5} & 40,000 and more than & 21 & 8.75 \\
\hline & Total & 240 & 100.00 \\
\hline & Loan amount Repaid by SHG members & & \\
\hline 1 & Up to $30 \%$ & 76 & 31.66 \\
\hline 2 & $30-50 \%$ & 62 & 25.83 \\
\hline 3 & $5070 \%$ & 54 & 22.50 \\
\hline \multirow[t]{3}{*}{4} & Above $70 \%$ & 48 & 20.00 \\
\hline & Total & 240 & 100.00 \\
\hline & Sources of SHGs loan & & \\
\hline 1 & Revolving fund & 83 & 34.58 \\
\hline 2 & Subsidy loan & 52 & 21.67 \\
\hline \multirow[t]{3}{*}{3} & SGSY & 105 & 43.75 \\
\hline & Total & 240 & 100.00 \\
\hline & Rate of interest on loan from bank & & \\
\hline 1 & 7.50 per cent & 181 & 75.42 \\
\hline \multirow[t]{2}{*}{2} & 8.50 per cent & 59 & 24.58 \\
\hline & Total & 240 & 100.00 \\
\hline
\end{tabular}

\section{Loan Practices Adopted:-}

Loan Practices Adopted:-

Majority about forty two per cent respondents borrowed loan only once whereas, about thirty one per cent borrowed up to 5000 from bank and maximum (31.66\%) respondents repaid loan up to $30 \%$. Maximum about forty four per cent respondents borrowed loan from SGSY and majority i.e. 75.42 per cent respondents borrowed Rs. Up to 25,000 and paid 7.5 per cent per annum interest to the bank.

Table 3:- Distribution of Respondents on the Basis of Entrepreneurial Activities N = 240.

\begin{tabular}{|c|l|c|c|c|}
\hline S.No & \multicolumn{1}{|c|}{ Entrepreneurial activities } & Regularly & \multicolumn{1}{c|}{ Occasionally } & Never \\
\hline A & Agricultural activities & $65(27.10)$ & $70(29.17)$ & $105(43.75)$ \\
\hline 1 & Vegetable \& seed production & $16(6.67)$ & $8(3.33)$ & $216(90.00)$ \\
\hline 2 & Honey bee keeping & $112(46.67)$ & $50(20.83)$ & $178(74.17)$ \\
\hline 3 & Dairy farming & $85(35.42)$ & $60(25.00)$ & $95(39.58)$ \\
\hline 4 & Goatary/ Poultry farming & $107(44.58)$ & $33(13.75)$ & $100(41.66)$ \\
\hline 5 & Vegetable vending & $32(13.33)$ & $59(24.58)$ & $149(62.08)$ \\
\hline 6 & Vermi compost \&NADEP & & \\
\hline B. & Non-Agricultural activities
\end{tabular}




\begin{tabular}{|c|l|c|c|c|}
\hline 1 & Food processing & $83(34.58)$ & $29(12.10)$ & $128(53.33)$ \\
\hline 2 & Agarbatti making & $8(3.33)$ & $94(39.17)$ & $138(57.50)$ \\
\hline 3 & Candle making & $13(5.42)$ & $128(53.33)$ & $99(41.25)$ \\
\hline 4 & Tailoring & $70(29.17)$ & $53(22.10)$ & $137(57.10)$ \\
\hline 5 & Flour milling & $3(1.25)$ & $2(0.83)$ & $235(97.92)$ \\
\hline 6 & Shop at local level & $133(55.42)$ & $00(0.00)$ & $107(44.58)$ \\
\hline 7 & Basket making/ mat making & $29(12.10)$ & $41(17.10)$ & $170(70.83)$ \\
\hline
\end{tabular}

(Figure in parenthesis indicates percentage)

\section{Entrepreneurial Activities:-}

About forty seven per cent respondents were 'regularly' engaged in "dairy farming" followed by 44.58 per cent respondents 'regularly' engaged in "vegetable vending". More than thirty five per cent respondents 'regularly' engaged in "goatary". Among non-agricultural activities, about fifty five per cent respondents were found 'regularly' engaged in "local level shop" followed by about thirty five per cent 'regularly' engaged in "food processing".

Table 4:- Relationship Between Empowerment of SHGs Members and Selected Independent variables. N = 240

\begin{tabular}{|c|c|c|c|c|}
\hline \multirow{2}{*}{ Variables } & \multicolumn{4}{|c|}{ Empowerment of SHGs Member } \\
\cline { 2 - 5 } & $\begin{array}{c}\text { Economic } \\
\text { empowerment }\end{array}$ & $\begin{array}{c}\text { Socio-cultural } \\
\text { empowerment }\end{array}$ & $\begin{array}{l}\text { Politico-legel } \\
\text { Empowerment }\end{array}$ & Self - Esteem \\
\hline Age & $0.2436^{*}$ & $0.2447^{*}$ & $0.2478^{*}$ & $-0.3280^{*}$ \\
\hline Education & -0.0692 & -0.0729 & 0.0744 & $0.2126^{*}$ \\
\hline Caste & 0.1120 & 0.0836 & 0.1054 & -0.1354 \\
\hline Family Size & -0.0191 & 0.0119 & -0.065 & 0.0410 \\
\hline Family type & $0.3586^{*}$ & -0.3008 & -0.3691 & $0.2501^{*}$ \\
\hline Type of house & $0.3384^{*}$ & $0.3323^{*}$ & $0.4115^{*}$ & $0.3288^{*}$ \\
\hline Occupation & $0.4490^{*}$ & $0.4238^{*}$ & $0.4433^{*}$ & $0.3595^{*}$ \\
\hline
\end{tabular}

(* Significant at 5.0\% level of significance)

To assess the relationship between empowerment of SHG members and selected independent variables correlation coefficient was assessed. The computed ' $r$ ' value showed that age is significantly positively correlated with all types of empowerment indicating as age increases economic empowerment, socio-cultural empowerment, politico-legal empowerment and self-esteem empowerment of respondent's also increase. Education is negatively correlated with economic empowered, socio-cultural empowerment, politico-legal empowerment but significant positive correlation was found between education and self -esteem empowerment. As education increases self-esteem empowerment of respondents also increases, as her level of education increase she understand her better and feel her own problems and find out solutions for them also.

No significant correlation was found between caste and economic, socio - cultural and politico-legal empowerment while negative correlation was found between self-esteem empowerment and caste. Family size was also negatively correlated with economic and politico-legal empowerment but positively correlated with socio cultural and self esteem empowerment. On the other hand family type was significantly positively correlated with self-esteem empowerment, respondents belonging to nuclear family were found more self-esteem empowered but family type was negatively correlated with economic, socio cultural and politico legal empowerment. Positive significant correlation was observed between type of house and economic empowerment, socio-cultural empowerment and politico-legal empowerment but negative correlation was found between type of house and self-esteem empowerment. Occupation was observed significantly positively correlated with economic empowerment, sociocultural empowerment and politico-legal empowerment as level of occupation increases economic, socio-cultural and politico-legal empowerment also increases but negative correlation was found between occupation and self esteem empowerment. Thus, null hypothesis is partially rejected on the basis of the above findings.

\section{Conclusion:-}

It is concluded from the present study that SHGs today play a major role in poverty alleviation in rural India. A growing number of poor people (mostly women) in various parts of India are the member of SHG and actively engage in saving and credit, as well as in other activities. Empowerment by way of participation in SHG brings 
enviable changes and enhances the living conditions of women in poor and developing countries like India. About ninety-six per cent respondents were strongly agreed upon "SHGs helped women to stop migration" and a majority of respondents were 'strongly agree' on SHGs "have little effect in changing an attitude of men towards women". Several factors and strategies have been provided by the SHGs that have made a positive contribution to the economic empowerment of women such as saving, credit and income generation thereby ensuring economic independence. When a woman becomes members of SHG, her sense of public participation enlarged, a horizon of social activities, high self- esteem, self-respect and fulfilments in life, expended and enhances the quality of status of women as a participant. Nearly ninety-two per cent respondents want to be Pradhan as they feel more confident since they come out from home and understand what is running in society so they also want to contribute their part for its betterment. SHGs are the major sources of inspiration for women's welfare. Women are an integral part of our country and economy. All round development and harmonious growth of nation would be possible only where women are considered as equal partners and SHG provides women a floor where she expresses herself and share responsibilities and thus, her self-confidence develop to its maximum and she reaches the top of her self-esteem.

\section{Reference:-}

1. Estape, G. and Torreguitart, C. 2010. Micro-1credit and women empowerment: An empirical case study based on Catalonia. ISTR International Conference, Istanbul.

2. Nagayya, D. and Rao D.K. 2009. Micro-finance and support organization in the southern States of India. Small Enterprise Development, Management and Extension Journal, 36 : 1-24.

3. Panda D.K. 2009. "Understanding Microfinance", Wiley India, New Delhi.

4. Sharma, A.K. and Sharma, A. 2010. Micro Financing Rural Women for Empowerment-Quo Vadis Microfinance and Women Empowerment. 